\title{
Patterns of adult roles, their antecedents and psychosocial wellbeing correlates among Finns born in 1959
}

\author{
Eija Räikkönen, Katja Kokko \\ University of Jyväskylä, Finland \\ eija.m.raikkonen@jyu.fi
}

Meichu Chen

Institute for Social Research, University of Michigan, USA

Lea Pulkkinen

University of Jyväskylä, Finland

\section{Abstract}

The study aimed to identify patterns of adult role combinations across the transitional domains of housing, educational attainment, work, partnership, and parenthood at age 27, and to investigate their antecedents and concurrent psychosocial wellbeing correlates. Data were derived for 354 Finns (born in 1959) from the Jyväskylä Longitudinal Study of Personality and Social Development. Three latent classes were identified: Work-orientation with delayed parenthood (WO; 46\%; completed adult transitions of independent living, education, work, and partnership), Traditional work and family (35\%; completed all five adult transitions), and Academic-orientation with no children (AO; 19\%; completed independent living, education, work, and partnership transitions). Individuals in the Traditional pattern were more likely to be women, whereas individuals in the AO and WO patterns were more likely to be men. The socio-economic status (SES) and structure of the family of origin did not differentiate the patterns, but individuals in the AO pattern had had higher school success and educational aspirations in adolescence than those in the other patterns. Early adult life satisfaction and career stability were higher, and depressive symptoms and binge drinking lower in the Traditional pattern than in WO. Life satisfaction was also higher in AO than in WO.

Keywords: adult roles, childhood, early adulthood, psychosocial wellbeing

\section{Introduction}

The life course of an individual has been conceptualized as "a sequence of socially defined, age-graded events and roles that the individual enacts over time" (Elder 1998, 941), suggesting that transitions between roles in different life domains are interdependent, and that understanding the structuring of the life course requires simultaneous consideration of these various dimensions (Macmillan and Copher 2005). In the global transition to adulthood, the key adult role transitions (adult transitions hereafter) include moving from parental home into independent living, completing full-time education, starting a full-time job, establishment of an intimate relationship, and becoming a parent (e.g. Arnett 2000; Furstenberg, Rumbaut and Settersten 2005; Shanahan 2000). However, few studies have operationalized the complex developmental nature of the transition to adulthood according to the aforementioned conceptualization of the life course. Instead, most of the studies conducted about transitions to adult roles have investigated them singly, more or less independent of one another (Furstenberg, Rumbaut and Settersten 2005) with some exceptions (Osgood et al 2005; Ross et al 2009; Räikkönen, Kokko and Rantanen, 2011; Sandefur et al 2005; Schulenberg et al 2005). Also the predictors 
and correlates of the transition patterns are unexplored. The aim of our study was to assess, within a representative sample of Finns born in 1959, patterns of role assumption in early adulthood, and the childhood antecedents and concurrent psychosocial wellbeing correlates of these patterns.

The timing and patterning of life transitions can be understood as a person's means to match decisions, commitments and career transitions with other life transitions, such as becoming a parent, as well as with contextual opportunities and constraints, as defined by Reitzle and Vondracek (2000). According to this definition, the individual is perceived as an active agent making decisions regarding his/her own life (Elder 1998; Elder, Kirkpatrick Johnson and Crosnoe 2003). These decisions, in turn, may affect subsequent transitions by opening or closing off opportunities, suggesting that transitions in different domains of life are interdependent.

In our study, we focused on variations in the combinations of adult roles across the domains of housing, education, work, partnership, and parenthood. Studies which have used personcentered typological approaches (e.g. latent class analysis) to investigate how different roles across these five domains weave together, suggest that the length and the level of post-comprehensive education and timing of family formation are crucial in determining transition patterns and role combinations at a particular age. The first typical pattern consists of individuals either lacking, or with short and low levels of post-comprehensive education, together with full-time work, marriage or cohabitation, and parenthood (Osgood et al 2005; Ross et al 2009; Sandefur, Eggerling-Boeck and Park 2005; Amato et al 2008; Oesterle et al 2010). The second typical pattern includes individuals who have obtained some post-comprehensive education, are working full-time, and have no family (Osgood et al 2005; Ross et al 2009; Sandefur, Eggerling-Boeck and Park 2005; Amato et al 2008). The third typical pattern consists of individuals who have a family but are disadvantaged with respect to career (Osgood et al 2005; Ross et al 2009; Amato et al 2008). The fourth pattern consists of those individuals who have obtained a higher level of education and who have postponed family formation (Osgood et al 2005; Ross et al 2009; Sandefur, Eggerling-Boeck and Park 2005; Amato et al 2008; Oesterle et al 2010). The fifth pattern is based on some empirical evidence regarding a group of individuals named as "slow starters" (Amato et al 2008) or "inactive" (Osgood et al 2005); that is, individuals who have assumed few or none of the adult roles.

The decisions regarding if, when, and in which order to undergo transitions, are always made in circumstances that are constrained by different background factors, such as gender, family of origin, and prevailing socio-historical and cultural context (Elder 1998; Shanahan 2000; Elder, Kirkpatrick Johnson and Crosnoe 2003; Schoon and Silbereisen 2009) as well as individuals' decisions made before the transitions. This interplay between the individual and the context has been described using the term bounded agency (Shanahan 2000). Our study focused upon the influences on the individual (i.e. gender, school success, and educational aspirations), the family, and the wider socio-historical and cultural context of the country in question (Finland). In the following paragraphs, we elaborate each of these influences and previous research on them.

\section{The Finnish context}

The present study was based on data collected from a representative sample of individuals born in 1959 in Finland (Pulkkinen 2006). In Finland, it has been typical for most youngsters to move out of the parental home at a fairly young age; women at 20 years and men at 21 years (Nikander 1998). The ages are similar for more recent age-cohorts. One reason for these early transitions to independent living is that the Finnish social welfare system provides a housing allowance for students who live in a rented apartment, to offset residential costs (Raivola, Zechner and Vehviläinen 2000). For those who are not students but otherwise have low incomes, Finnish society also provides a housing allowance (Saarikallio and Ylöstalo 2007).

The basic structure of the Finnish educational system has remained similar since the 1970s (Sahlberg 2011). Comprehensive school lasts for 9 years (from age 7 to 16). After that, youngsters enter either general upper secondary school (3 years) for post-comprehensive education, vocational upper secondary school (2-3 years depending on the study 
program), or the labor market (Sahlberg 2011; Statistics Finland 2003). Selection to general and vocational upper secondary schools is based on the interests and grades of students. Vocational school qualifies young people only for vocational college (nowadays polytechnics) whereas upper secondary school qualifies them for tertiary education (i.e. either vocational college or university) (Sahlberg 2011).

The cohort born in 1959 was completing comprehensive school at a time when (1975) it was relatively easy to transfer directly from school to fulltime work; the unemployment rate then was $2.6 \%$ (Statistics Finland 2003). The unemployment rate stayed at a relatively low level until the early 1990s recession, but in 1992, the unemployment rate was already $11.7 \%$. However, most young people throughout this period decided to continue in fulltime education; almost 3 in 4 Finnish adults aged 2564 have qualified from upper secondary or tertiary education. An important reason for this high percentage continuing their studies is that all postcomprehensive education is and was free up to the university level (Kokko et al 2008). It is typical of Finland that students are on average around 25 to 29 years old when they graduate from university. There are several reasons for this, such as a competitive university entrance system, which delays the start of studies, and the fact that students usually take a Master's degree, which is a common requirement in the labor market. Moreover, men are obliged to participate in either military or civil service (optional also for women) before their $29^{\text {th }}$ birthday.

A further distinctive feature of Finnish society is an equal engagement in full-time employment among women and men (Lehto and Sutela 2008). Part-time work with reduced working hours for mothers has been common in other Nordic countries. However in Finland, it is relatively rare, even among mothers with young children: in 1984, only $7 \%$ of Finns worked part-time.

Regarding family-related transitions, the mean age for getting married for the first time was 25.9 years in women and 28.1 years in men in 1986-1990, and the mean age of first childbirth was 26.5 years (Statistics Finland 2003). Finnish men are about two years older than women when they become a parent for the first time (Statistics Finland 1994). Highly educated women become parents later than other groups; they are about two years older at first childbirth than women who have not obtained a Master's degree. In Finland, cohabitation before marriage or as an alternative to marriage has been popular for many years. Among women born in 1938-42, 13\% had lived in cohabitation, but among women born in 1958$62,51 \%$ had lived in cohabitation before marriage and $33 \%$ as an alternative to marriage.

\section{Socio-demographic and individual influences}

Factors that differentiate transition behaviors include gender, the socio-economic status (SES) and structure of the family of origin, and personal choices. Although the educational and work pathways of women and men have become similar in the past few decades (Fussell and Furstenberg 2005), women and men still seem to differ in their pathways to adulthood: empirical studies based on older and more recent age-cohorts have demonstrated that women undergo adult transitions earlier than men, particularly in the family domain (Cohen et al 2003; Oesterle et al 2010; Kokko, Pulkkinen and Mesiäinen 2009). The timing of different transitions may also be more closely interlinked among women than among men (Kokko, Pulkkinen and Mesiäinen 2009). Factors related to an individual's family of origin may also influence transition behaviors: individuals from low SES families tend to undergo adult transitions earlier than those from higher socio-economic backgrounds, for whom the later timing of transitions is more typical (e.g. Osgood et al 2005; Sandefur, EggerlingBoeck and Park 2005; Schoon, Martin and Ross 2007). This is most likely due to differences in the level of educational attainment: low family SES and earlier timing of transitions are associated with lower educational attainment (Kokko et al 2008). An impact of the structure of the family of origin on transitions was found in the study by Ross and his colleagues (2009), which showed that individuals who grew up in divorced families were less likely to pursue their educational career in post-secondary education, and more likely to establish their own families at an earlier age. Individuals' own educational aspirations, 
expectations, and performance in school may also differentiate transition behaviors (Osgood et al 2005; Ross et al 2009; Schoon, Martin and Ross 2007).

The transition to adulthood provides new roles and social contexts, and the successes and difficulties one experiences with the many challenges during this period may strengthen or alter the ongoing trajectories of substance use, health and wellbeing (Schulenberg et al 2005; Schulenberg, Bryant and O'Malley 2004). In general, the average levels of wellbeing and substance use have been found to increase from late adolescence to early adulthood (Schulenberg et al 2005). The average level of wellbeing tends to increase across adulthood (Räikkönen, Kokko and Rantanen 2011) whereas the average level of binge drinking has been shown to peak in early adulthood and then decrease (Schulenberg et al 2005). However, studies suggest that engagement in family roles, particularly marriage or cohabitation, reduces the use of substances (Schulenberg et al 2005; Staff et al 2010) and enhances one's wellbeing (Schulenberg et al 2005; Lee and Gramotnev 2007). By contrast, postponing transitions to stable adult roles beyond early adulthood has been linked to lower levels of wellbeing (Räikkönen, Kokko and Rantanen 2011;
Schulenberg et al 2005) and higher levels of binge drinking (Schulenberg et al 2005) in early adulthood.

\section{Aims and hypotheses}

The first aim of the present study was to identify patterns of adult role combinations in early adulthood by investigating five transition domains (i.e. moving into independent living, completion of education, full-time employment, having an intimate relationship, and having a child) simultaneously (Figure 1). Taking into account the cultural features of Finland, as well as the Jyväskylä Longitudinal Study of Personality and Social Development (JYLS) data collection phases, we chose age 27 as the cut-off point. Completion of education means that a participant has obtained a degree from vocational school, vocational college, or university. We expected to find at least three latent classes: 1) a group of individuals who have undergone all adult transitions by age 27 ; 2) a group of individuals who have followed an academic path to adulthood, and because of their extended studies, their family formation is delayed; 3) a group of individuals who have undergone few of the five transitions (e.g. Ross et al 2009).

Figure 1. Conceptual model of the study. The Roman numerals I - III index the research questions of the study.

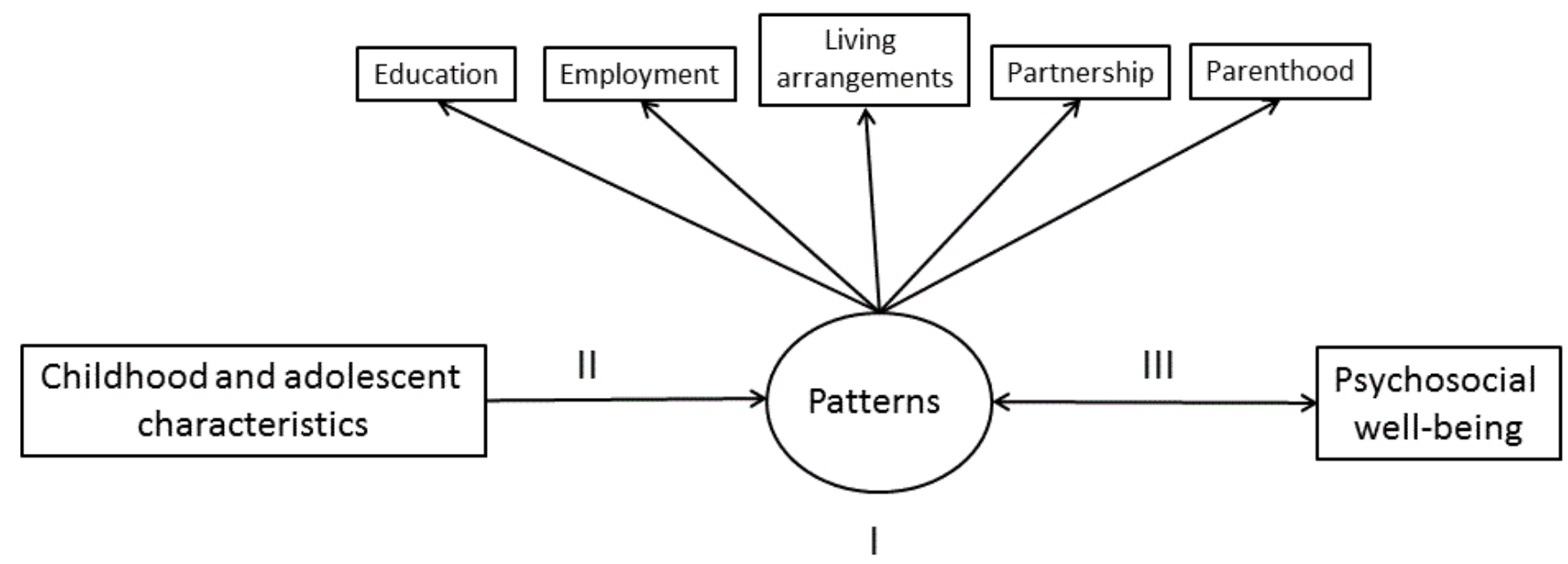


Our second aim was to investigate whether individual agency and contextual characteristics contribute to the identified latent classes (Figure 1). Context was operationalized by gender, family SES, and intact/non-intact family structure (Ross et al 2009), while individual agency was conceptualized in relation to school success and educational aspirations (Schoon, Martin and Ross 2007). Orientation to studies reflects individual agency concerning transitions in education. We expected that women would have experienced all five transitions more typically than men by age 27 , because women are, on the average, two years younger than men at the time of marriage and the birth of the first child, and because women and men are equally educated and also employed in Finland, due to day care services for all children. Furthermore, we expected that individuals in the academic path would have experienced fewer transitions, because moreeducated individuals tend to delay the birth of the first child (Statistics Finland 1994). Fewer completed transitions were expected to be found among individuals who have had difficulties in the completion of education and employment. In relation to background factors, we expected that high SES of the family of origin, good school success and high educational aspirations would be associated with the academic path, compared to the path including fewer completed transitions (Schoon, Martin and Ross 2007). The stability of the family of origin was expected to be associated with the pattern of all five transitions by age 27 (Ross et al 2009).

Our third aim was to examine whether the identified latent classes would differ in psychosocial wellbeing measured at age 27 (Figure 1). We defined psychosocial wellbeing in terms of life satisfaction, depressive symptoms, stability of career line, and binge drinking. We assumed that individuals with fewer completed adult transitions would show lower levels of psychosocial wellbeing compared to other groups (e.g. Schulenberg et al 2005).

\section{Methods}

\section{Sample}

The present study used data from the ongoing Jyväskylä Longitudinal Study of Personality and Social Development (JYLS) study, in which the same individuals have been followed from age 8 to age 50
(Pulkkinen 2006; Pulkkinen and Kokko 2010). The study was begun by Lea Pulkkinen in 1968, when she randomly selected 12 complete second-grade classes in the town of Jyväskylä, Finland, for the study; all the pupils participated (i.e. the initial participation rate was $100 \%)$. The original sample consisted of 173 girls and 196 boys, of whom the majority (94\%) was born in 1959; the rest were born either in 1958 or 1960. The mean starting age of the participants was 8.3 years $(S D=.25)$. All participants were native Finns. After age 8, main data collection phases took place at ages $14,27,36,42$, and 50 . In the present study, adult transitions were studied up to age 27.

At ages 8 and 14, data were gathered using peer nominations and teacher ratings (Pulkkinen 2006). At age 14 (in 1974), the sample size was 167 girls (97\% of the original sample) and 189 boys (96\%). At age 27 (in 1986), the methods of data collection were a mailed Life Situation Questionnaire (LSQ) and a semistructured interview. The LSQ was completed by 155 women (90\%) and 166 men (85\%), and interviews conducted with 142 women (82\%) and 150 men (77\%).

Information about adult transitions was gathered using the LSQs administered at ages 27, 36, 42, and 50 , and retrospectively using the Life History Calendar (LHC; adapted from Caspi et al 1996) at ages 42 and 50. As a result of this procedure, the number of participants in the present study was 354 (95.9\% of the initial sample; 165 women and 189 men). Both at ages 42 and 50, the sample was representative of the original random sample (studied at ages 8 and 14 in regard to social behavior and school success) and their age-cohort born in Finland in 1959, when compared with data provided by Statistics Finland on, for instance education, occupational status and marital status (Pulkkinen 2006; Pulkkinen and Kokko 2010).

\section{Measures and Variables}

Adult role combinations in the following five transition domains were examined: Educational attainment, employment, living arrangements, partnership, and parenthood. The variable for educational attainment measures the highest degree obtained by age 27. Educational attainment was coded 1 = no post-comprehensive education, 2 = vocational school, $3=$ vocational college, and $4=$ 
university. A degree refers to graduation from a vocational school, vocational college, or university. The variable for living arrangements describes whether or not a participant has moved out from the parental home by age 27 . It was coded $0=$ lives with parents, 1 = lives away from parents. The variable for employment was coded in five categories: 1 = out of labor force, 2 = full-time homemaker, 3 = full-time student, 4 = part-time work, and 5 = full-time work. The category 'full-time work' included only those participants who had worked full-time by age 27 . If a participant had not worked full-time by age 27 , then the status at age 27 was coded. The partnership variable was coded in two stages. First, partnership status at age 27 (married, cohabiting, divorced, separated after a cohabitation, or single) was coded for each participant. "Single" denoted a participant who had never been married or cohabited by age 27 . Second, categories of "divorced", "separated", and "single" were combined. Partnership was coded $1=$ marriage, 2 = cohabitation and $3=$ single. The twostage coding of the partnership variable enabled us to trace, when necessary, all those participants who had completed the relationship transition by age 27 . Parenthood was coded $1=$ no children, $2=$ one child and $3=$ two children or more. Distributions of each transition variable are presented in Table 1.

Table 1. Observed role characteristics in the JYLS sample $(N=354)$ by age 27.

$\begin{array}{lcc}\text { Education } & & 352 \\ \text { No post-comprehensive education } & 31.81 & 112 \\ \text { Vocational school } & 42.05 & 148 \\ \text { Vocational college } & 15.34 & 54 \\ \text { University } & 10.80 & 38 \\ \text { Employment status } & & 346 \\ \text { Unemployed/out of labor force } & 2.02 & 7 \\ \text { Full-time home maker } & 1.73 & 6 \\ \text { Full-time student } & 5.20 & 18 \\ \text { Part-time work } & 1.73 & 6 \\ \text { Full-time work } & 89.30 & 309 \\ \text { Living arrangements } & & 345 \\ \text { Lives away from home } & 95.94 & 331 \\ \text { Lives with parents } & 4.06 & 14 \\ \text { Relationship status } & & 344 \\ \text { Marriage } & 47.09 & 162 \\ \text { Cohabitation } & 22.10 & 76 \\ \text { Single } & 30.81 & 106 \\ \text { Parental status } & & 346 \\ \text { No children } & 53.47 & 185 \\ \text { 1 child } & 27.75 & 96 \\ 2 \text { or more children } & 18.78 & 65 \\ & & \end{array}$


Childhood and adolescent predictors

Gender was coded $0=$ female, $1=$ male. Socioeconomic status of the family of origin was coded when the child was 8 years old, on the basis of the father's occupation (the mother's occupation was used if she was a sole provider) into two categories: 0 = blue-collar and 1 = white-collar worker (Pitkänen, Lyyra and Pulkkinen 2005). Family structure at age 14 was coded $O$ for intact family (i.e. the participant lived with both parents) and 1 if the parents had divorced, separated from cohabitation or a parent had died (Pulkkinen, Lyyra and Kokko 2009). School success at age 14 was measured by grade point average (min. 4, max. 10). The information about school success was collected from school archives. The observed range for school success was 5.3-9.1 (Table 2). For the purposes of the present study, school success was centered around its mean (7.22; see Table 2). We used actual entrance to upper secondary school (qualifying for tertiary education) as an indicator of participants' educational aspirations (Pitkänen et al 2008). For the purposes of the present study, educational aspirations were coded using two categories: 0 = other, 1 = upper secondary school.

Table 2. Descriptive statistics for childhood and adolescent antecedents, and early adult psychosocial wellbeing correlates. Means and standard deviations (in parentheses) are reported for continuous variables, and percentages for categorical variables.

\section{Childhood and adolescent antecedents}

Gender (1 = male)

Family SES at age 8 ( 1 = white-collar workers)

Family structure at age 14 ( 1 = non-intact family)

Educational aspiration at age 14 ( 1 = upper secondary school)

Grade point average at age 14

Psychosocial wellbeing at age 27

Life satisfaction

Career stability

Unstable

Changeable

Stable

Depressive symptoms

Binge drinking

Not at all

Once a year or less

Less than once a month

1-3 times a month

Once a week

Several times a week
Mean (sd)/\% $\quad \boldsymbol{N}^{1}$

53.40

354

$28.81 \quad 354$

$23.78 \quad 349$

$39.94 \quad 343$

$7.22(.87) \quad 332$

$2.97(.43) \quad 322$

335

23.28

7.46

69.25

$1.98(.46) \quad 320$

323

21.05

7.43

34.06

21.36

12.38

3.72

Note: ${ }^{1} \mathrm{~N}$ is the number of non-missing cases for each variable. 
Psychosocial wellbeing at age 27 was assessed by life satisfaction, depressive symptoms, stability of career line, and binge drinking. Life satisfaction was assessed using five questions presented in the mailed LSQ. With these questions, we sought to assess a broader construct of global life satisfaction. The questions concerned satisfaction with housing, financial situation, choice of occupation, present occupational situation, and content of leisure time. The response scale ranged from 1 = very dissatisfied to $4=$ very satisfied. Statistically significant correlations between the items ranged from .11 to .50 . Satisfaction with leisure time did not correlate with housing and financial situation. An average score was computed, and Cronbach's alpha was .56 (Feldt, Mäkikangas and Aunola 2006).

Depressive symptoms was a subscale of a Personal Control Inventory presented in the mailed LSQ. The subscale was composed of five items (e.g. "I feel despair."). The response scale ranged from 1 (strongly disagree) to 4 (strongly agree; Pulkkinen and Rönkä 1994). An averaged score was computed and Cronbach's alpha was .65.

Stability of career line was evaluated on the basis of several questions presented in the LSQ and interview. The follow-up covered 11 years, from 1975 to 1986 (i.e. from age 16 to 27) (Rönkä, Kinnunen and Pulkkinen 2000). Three categories were formed: $1=$ unstable career (including participants who had experienced long periods of unemployment); 2 = changeable career (including participants whose jobs had varied and for the most part did not correspond to their field; those who had started studying; those whose work situation had suddenly become unstable; or those who had removed themselves from the work force in order to care for children); $3=$ stable career (including participants who had worked in their own field without repeated interruptions due to unemployment, or had a career which had become stable during the first years of the follow-up period). Women who had been on maternity leave, but who had returned to their jobs after the leave, were coded as having a stable career.

Binge drinking for occasions of drunkenness During the interview, the participants were asked to recall how often during the past 12 months they had consumed so much alcohol that they had been truly drunk. Furthermore, in the mailed LSQ, the participants were asked to complete a quantityfrequency (q-f) table with the following instruction:
"How much alcohol do you drink in one session? If you have stopped drinking, please refer to the situation before you quit. Circle the most appropriate option on each line." The quantity options consisted of different portion estimates per occasion: 1 drink or less, 2-4 drinks, or 5 drinks or more. One drink (portion of alcohol) was defined as one bottle $(33 \mathrm{cl})$ of beer ( $4.5 \%$ alc.), one glass of wine $(12 \mathrm{cl} \sim 12 \%$ alc.), one glass of strong wine $(8 \mathrm{cl} \sim 21 \%$ alc.) or one $4 \mathrm{cl}$ shot of spirits. Binge drinking was operationalized on the basis of the reported times of being truly drunk, but adjusted for the frequency of drinking at least five portions per occasion as reported in $q-f$ table presented in the mailed LSQ. The variable for binge drinking was coded $0=$ not at all, $1=$ once a year, $2=$ less often than once a month, $3=$ one to three times a month, 4 = once $a$ week, and 5 = several times a week (Pitkänen et al 2008).

\section{Analytic Strategy}

The analyses of the present study were conducted in three phases. First, the patterning of adult roles was examined using latent class analysis (LCA). LCA is a statistical method that enables the examination of latent structures among a set of categorical variables (Lazarsfeld and Henry 1968). In the present study, five categorical variables were used: residence, educational attainment, employment status, partnership status, and parenthood. The parameters of the LCA model are proportions of individuals within each of the latent classes (i.e. latent class probabilities) and their distribution across the predictor variables in a given latent class (i.e. conditional probabilities) (Nylund, Asparouhov and Muthén 2007). An advantage of using LCA instead of conventional cluster analysis, is that it provides several model fit indices, which enable the assessment of the model fit to the data, and the appropriateness of the number of latent classes specified. In addition, because LCA is a model-based method, the same results can theoretically be replicated with an independent sample (Muthén and Muthén 2000). The following indices are employed in our study: Bayesian Information Criterion (BIC) (Schwartz 1978), adjusted Bayesian Information Criteria (aBIC) (Sclove 1987), and Bootstrap Likelihood Ratio Test (BLRT) (Nylund, Asparouhov and Muthén 2007). Lower values of $\mathrm{BIC}$ and $\mathrm{aBIC}$ indicate a better fitting model. BLRT $p$ values above 0.05 indicate a good fit of the specified LCA 
model, while values below 0.05 indicate that the number of classes should be increased by one (Nylund, Asparouhov and Muthén 2007). In addition, entropy (Celeux and Soromenho 1996) and interpretability of latent classes (Muthén and Muthén 2000) are considered when choosing the optimal number of latent classes. Entropy values approaching 1 indicate clear delineation of classes and that individuals are placed into classes with high precision (Celeux and Soromenho 1996).

Second, after deciding the best LCA solution, multinomial logistic regression analyses were conducted to investigate the extent to which childhood and adolescent characteristics predicted membership of the latent classes (Figure 1). Regression coefficients were presented as odds ratios $(O R)$. An $O R$ is the ratio of the odds of being in a particular latent class $k$ (versus being in the reference class $j$ ) for any value $b$ of a particular childhood characteristic, to the odds of being in class $k$ for value $b+1$ of the childhood characteristic. For example for a dichotomous covariate, the $O R$ represents change in the odds of being in a class $k$ (versus being in the reference class $j$ ), when the value of a particular childhood characteristic changes from 0 to 1 . An $O R$ greater than one indicates that those individuals with the characteristic (i.e. for whom the value of the childhood characteristic is 1) are more likely to be in the class $k$ than those individuals without the characteristic. Each latent class was in turn used as a reference class in order to compare each latent class to all other latent classes. In addition to $O R s$, we report relative risks $(R R)$ in order to provide the reader with a direct comparison of the present results with the results shown in the study by Salmela-Aro, Ek, Taanila and Chen (2012, this issue). A $R R$ is a ratio of two probabilities. $R R$ indicates how many times more likely a participant is to be a member of a latent class $k$ given a one unit increase in a childhood characteristic. For example for a dichotomous characteristic, $R R$ represents the ratio of the probability of being in class $k$ for characteristic category 1 , versus the probability of being in class $k$ for category 0.

Third, multivariate analysis was conducted to examine whether membership in the latent classes predicted psychosocial wellbeing in early adulthood (Figure 1). Regression analysis was used for continuous wellbeing outcomes (i.e. life satisfaction and depressive symptoms) and ordered logistic regression analysis was used for ordinal wellbeing outcomes (i.e. career stability and binge drinking). A set of dummy indicators of latent class membership was used as independent variables to estimate class differences in outcomes. In order to compare each latent class to all other latent classes, each latent class was set by turns as a reference group (i.e. each dummy was excluded by turns). The childhood and adolescent variables were controlled for in the analyses, in order to rule out the possibility that the observed differences between the latent classes in wellbeing indicators would result from the childhood and adolescent factors.

All analyses were conducted using the Mplus statistical package version 6.0 (Muthén and Muthén 1998-2010). In all analyses, the method of estimation was that of full information maximum likelihood (FIML) implemented in Mplus. FIML uses all observations in a data set when estimating the parameters in the model, without imputing the missing values. The models for the second and the third stages were estimated simultaneously to maximize the information in the data for estimation, the error terms between continuous measures of psychosocial wellbeing were allowed to correlate, and MLR estimator with Monte Carlo integration approach was used in the estimation process.

\section{Results}

\section{Descriptive results}

The descriptive statistics for childhood predictors and correlates for early adult psychosocial wellbeing are shown in Table 2. Some gender differences were found in the predictors and correlates. Women were more likely to enter upper secondary school qualifying for university $\left(\chi^{2}(2)=20.36, p<.001\right.$, Adjusted standardized residual $(A S R)=4.4)$ than men, for whom it was more typical to enter vocational school $(A S R=$ 3.4). Women also had better school success than men $(t(271)=7.64, p<.001)$. Regarding wellbeing, gender differences were found in binge drinking $\left(\chi^{2}(5)=71.08\right.$, $p<.001)$. Men were more likely to report binge drinking 1-3 times a month $(A S R=4.0)$, once a week $(A S R=4.8)$, or several times a week $(A S R=3.4)$ whereas women were more likely to report drinking binge less than once a month $(A S R=5.1)$ or not at all $(A S R=3.0)$. 


\section{Latent Classes}

Fit statistics for the estimated latent class models showed that the 3-class model had the best fit indices, but also 2 - and 4-class models received some support (Table 3). However, the interpretability of the 2- and 4- class models was not as good as that of the 3-class model. Therefore, we chose the three class model as the final model.

Table 3. Model fit indices for estimated latent class solutions.

$\begin{array}{ccccc}\text { Number of classes } & \text { BIC } & \text { aBIC } & \text { BLRT } \boldsymbol{p} \text {-value } & \text { Entropy } \\ 2 \text { classes } & 2739 & 2659 & 0.000 & 0.837 \\ 3 \text { classes } & 2776 & 2655 & 0.002 & 0.805 \\ 4 \text { classes } & 2830 & 2668 & 0.072 & 0.836 \\ 5 \text { classes } & 2884 & 2681 & 0.070 & 0.789\end{array}$

Note. $B I C=$ Bayesian Information Criteria $; a B I C=$ adjusted Bayesian Information Criteria; $B L R T=$ Bootstrap Likelihood Ratio Test.

\section{Table 4. Latent class probabilities and conditional probabilities ${ }^{1}$

$\begin{array}{ccc}\begin{array}{c}\text { Work-orientation } \\ \text { with delayed } \\ \text { parenthood }\end{array} & \begin{array}{c}\text { Traditional } \\ \text { work and family }\end{array} & \begin{array}{c}\text { Academic- } \\ \text { orientation with } \\ \text { no children }\end{array}\end{array}$

\section{Education}

No post-comprehensive education

Vocational school

Vocational college

University

Employment status

Unemployed/out of labor force

Full-time home maker

Full-time student

Part-time work

Full-time work

\section{Living arrangements}

Lives with parents

Lives away from home

Relationship status

Marriage

Cohabitation

Single

Parental status

No children

1 child

2 or more children

Class $N^{2}$

Latent class probabilities ${ }^{2}$

Notes.

${ }^{1}$ Latent class probabilities are proportions of individuals within each of the latent classes and conditional probabilities are their distribution across the indicator variables in a given latent class.

${ }^{2}$ Values from classification of individuals based on their most likely class membership.
.347

.568

.085

.000

.037

.000

.000

.019

.944

.077

.923

.000

.421

.579

.753

.204

.043

163

0.460

.356

.423

.147

.074

.007

.050

.033

.024

.886

.161

.000

.359

.480

.000

.000

.237

.000

.763

.000

1.000

.246

.254

.500

.000

1.000

.516

.000

.484

124

67

0.189

0.350

.000 conditional 
Table 4 presents the latent classes and the conditional probabilities of the chosen model. Class proportions are presented in Figure 2. Almost all participants in the three classes were living independently $(95.9 \%$ of the sample; Table 1). Members of the largest class, Workorientation with delayed parenthood (46.0\%; Table 4) typically had undergone four of the five transitions by age 27: They had moved from the parental home, obtained a degree from a post-comprehensive educational institution, worked full-time, had been in a committed relationship, and had no children. Half of the group had an educational degree from a vocational school. At age 27, their partnership status was mixed: the class included single and cohabiting individuals. Additional analysis showed that $20.8 \%$ of the members in the Work-orientation were truly singles (i.e. they had never been married or cohabited).

Figure 2. Percentages of JYLS latent classes $(N=354)$.

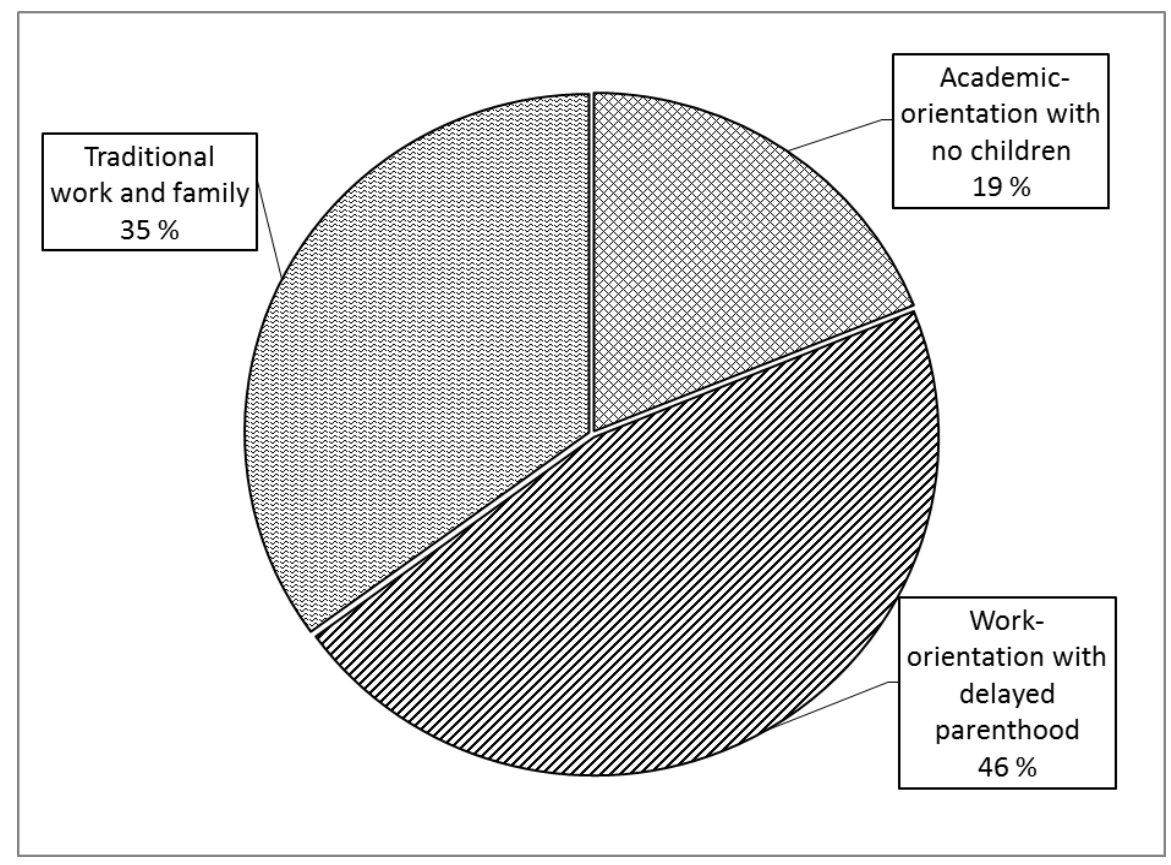

Members of the second class, Traditional work and family (35.0\%; Table 4) had typically undergone all five adult transitions by age 27 , that is, most of them lived independently, had a degree from a post-comprehensive educational institution, they worked full-time and they were married with at least one child. Almost half of the members of this class had an educational degree from a vocational school.

Members of the smallest class, Academic-orientation with no children (18.9\%; Table 4) typically had undergone four of the five adult transitions: They had moved from the parental home, obtained a degree from a postcomprehensive educational institution, worked full-time, had been in a committed relationship, and had no children. At age 27, their partnership status was mixed the class included single, cohabiting, and married participants. Additional analysis showed that $37.3 \%$ of the members in the Academic pattern were truly singles (i.e. they had never been married or cohabited).

\section{Antecedents of Class Membership}

Women were more likely to be in the Traditional pattern than in the Academic and Work-orientation patterns (Tables 5 and 6). No gender differences were found between the Academic and Work-orientation patterns. Individuals who had achieved higher school success and entered upper secondary school at age 14 were more likely to be in the Academic pattern than in the Traditional and Work-orientation patterns. The structure and socio-economic status of the family of origin did not significantly contribute to the class membership. 
Table 5. Patterns of adult role combinations in relation to childhood and adolescent antecedents: multinomial logistic regression analysis with odds ratios (OR) and $95 \%$ confidence intervals $(\mathrm{Cl})$.

\section{Childhood and \\ adolescent characteristics}

Male (vs. female)

White-collar (vs. blue-collar SES)

Lives with one parent (vs. parents together)

Grade point average

Educational aspirations

(upper secondary school vs. other)

Note. ${ }^{*} p<.05 ;{ }^{* *} p<.01 ;{ }^{* * *} p<.001$.

\section{Traditional vs.}

Work-orientation

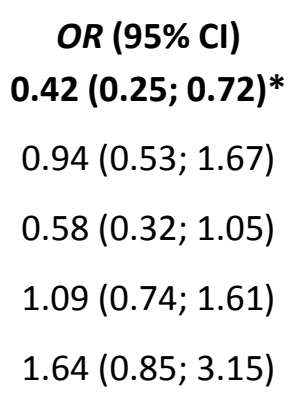

Academic- vs.

Work-orientation

OR $(95 \% \mathrm{Cl})$
$1.41(0.63 ; 3.17)$
$1.45(0.69 ; 3.05)$
$0.82(0.35 ; 1.93)$
$3.21(1.84 ; 5.61)^{* * *}$
$22.02(6.98 ; 69.44)^{* * *}$

Academic-orientation

vs. Traditional

$$
\begin{gathered}
O R(95 \% \mathrm{Cl}) \\
3.36(1.49 ; 7.56)^{* *} \\
1.54(0.75 ; 3.18) \\
1.41(0.57 ; 3.48) \\
2.96(1.68 ; 5.23)^{* * *} \\
13.43(4.26 ; 42.35)^{* * *}
\end{gathered}
$$

Table 6. Patterns of adult role combinations in relation to childhood and adolescent antecedents: relative risks.

\section{Childhood and adolescent characteristics}

Male (vs. female)

White-collar SES (vs. blue-collar)

Lives with one parent (vs. parents together)

Grade point average $1 \mathrm{sd}$ above vs. average

Educational aspirations (upper secondary school vs. other)

$\begin{gathered}\text { Work-orientation with } \\ \text { delayed parenthood }\end{gathered}$
1.452
1.025
1.299
0.929
0.611

\section{Traditional work and family}

$$
0.610
$$$$
0.967
$$

0.757

1.007

1.001
Academic-orientation with no children

2.048

1.489

1.068

2.981

13.442 
Table 7. Patterns of adult role combinations in relation to psychosocial wellbeing: multivariate analysis.

Regression coefficients and their standard errors (s.e. in parentheses) in each latent class are reported for all outcomes. In addition, odds ratios (OR) are presented in the case of categorical outcomes.

$\begin{array}{cc}\text { Life } & \text { Depressive } \\ \text { satisfaction } & \text { symptoms } \\ b \text { (s.e.) } & b \text { (s.e.) }\end{array}$

\section{Comparison group: Work-orientation}

Traditional work and family

Academic-orientation with no children

Comparison group: Traditional work and family

Academic-orientation with no children

Note. ${ }^{*} p<.05 ;{ }^{* *} p<.01 ;{ }^{* * *} p<.001$.

$\begin{array}{ll}0.18(.05)^{* * *} & -0.13(.06)^{*} \\ 0.15(.08)^{*} & -0.01(.08)\end{array}$

$-0.03(.07)$

$0.122(.08)$

$-0.34(.50)$

$0.62(.29)^{*}$

$0.27(.47)$

\section{Career stability} $b(s . e$.

1.84

1.31

$-0.66(.24)^{* *}$

$-0.06(.33)$

0.71

$0.60(.33)$

1.82 


\section{Psychosocial wellbeing at age $\mathbf{2 7}$}

Individuals in the Traditional pattern reported higher life satisfaction and career stability as well as less depressive symptoms and binge drinking at age 27 than individuals in the Work-orientation pattern (Table 7). Individuals in the Academic pattern showed higher level of life satisfaction than individuals in the Work-orientation pattern. No differences were found between Traditional and Academic patterns.

\section{Discussion}

In the present study, we investigated the patterning of adult roles across the domains of housing, educational attainment, employment, partnership, and parenthood in early adulthood, as well as their childhood and adolescent antecedents and contemporaneous psychosocial wellbeing correlates. Our analyses were based on a representative sample of Finns born in 1959. We identified three patterns: Work-orientation with delayed parenthood, Traditional work and family; Academic-orientation with no children. Our three patterns of adult role combinations corresponded fairly well to classes found in earlier studies using latent class analysis (e.g. Oesterle et al 2010; Osgood et al 2005; Ross et al 2009; Sandefur, Eggerling-Boeck and Park 2005). Thus, although the transition to adulthood has lengthened, diversified, and become more heterogeneous in the timing and content of role changes in most western countries in recent decades (e.g. Arnett 2000; Furstenberg, Rumbaut and Settersten 2005; Shanahan 2000), the transitional patterns appear to be rather similar across countries in early adulthood.

Unsurprisingly, the majority of our participants lived independently. Hence, housing situation did not distinguish the patterns. In Finland, it is typical for young adults to move out from the parental home at an early age (Nikander 1998). This applies both to the 1959 cohort and to more recent age cohorts. One reason for this young age is that Finnish society provides a housing allowance to offset residential costs for students and those with low income for other reasons (Raivola, Zechner and Vehviläinen 2000; Saarikallio and Ylöstalo 2007). As in previous studies (e.g. Osgood et al 2005; Ross et al 2009, Sandefur, Eggerling-Boeck and Park 2005), transitions in relation to educational attainment and family formation distinguished our patterns most clearly. As indicated by the group name, individuals in the Academic-orientation with no children had obtained a high level of education, whereas individuals in the other two groups had lower levels of postcomprehensive education. Among those individuals who had obtained a more limited amount of education, two groups were found: first, individuals who had become parents (Traditional pattern), and second, individuals who had no children (Workorientation pattern).

Contrary to our expectations (e.g. Ross et al 2009), we did not find a pattern of individuals who had undergone few (less than four) of the adult transitions. Instead, we found two patterns of individuals (Academic and Work-orientation) who had one delayed transition: parenthood. The Workorientation pattern was the most prevalent pattern, covering over two fifths of our sample. This pattern as well as the Academic pattern could be considered to represent those individuals who are experiencing a delayed step into adult roles, a period which has recently been labeled as emerging adulthood (Arnett 2000).

Our results indicated that both background and individual agency-related characteristics contributed to membership of the patterns of adult role combinations, supporting the idea of bounded agency (Shanahan 2000). Our findings showed that women were over-represented in the family-oriented pattern, namely Traditional work and family. This result reflects earlier findings which have shown that women establish a family at an earlier age than men (Cohen et al 2003; Kokko, Pulkkinen and Mesiäinen 2009). Furthermore, as in earlier studies (e.g. Ross et al 2009), individuals in the Academic pattern had better school success and higher educational aspirations (indicated by the entrance to upper secondary school qualifying for tertiary education) than individuals in the Traditional and Workorientation patterns. Contrary to our expectations (e.g. Schoon et al 2007), family SES did not distinguish our patterns. One reason for these findings may be that in Finland, socio-economic differences are relatively small, education is free up to university level (Kokko et al 2008), and housing allowances were provided for students who lived in rented apartments, to offset residential costs (Raivola, 
Zechner and Vehviläinen 2000). Consequently, due to these readily available opportunities provided by Finnish society, it was more possible for individuals with different social backgrounds to follow the path they preferred than, for instance, might be the case in countries where there are tuition fees.

Our results showed that individuals in the Traditional and Academic patterns showed higher life satisfaction than individuals in the Work-orientation pattern. Furthermore, individuals in the Traditional pattern reported higher career stability and less depressive symptoms and binge drinking than individuals in the Work-orientation pattern. Regarding those individuals with a limited amount of postcomprehensive education, our results suggest that the relatively early completion of adult transitions seems to be associated with higher levels of wellbeing. Furthermore, in Finland, communities are obliged to provide a child care service, which enables mothers to work full-time outside the home. Therefore, becoming a parent is not an obstacle to having a stable career. Regarding the difference in life satisfaction among those who had one missing transition (Academic and Work-orientation patterns), our results indicate that individuals in the Academic pattern had a higher level of life satisfaction because they had obtained a higher level of postcomprehensive education than individuals in the Work-orientation pattern. Accordingly, it has been shown that having a higher level of education is associated with higher life satisfaction than having a lower level of education (Daukantaite and Zukauskiene 2006). However, based on our wellbeing results, no conclusions about causal links between the completion of transitions and psychosocial wellbeing can be drawn, because the wellbeing measures used in our study were not available before age 27. The examination of causal associations between wellbeing and transitions, remains for the future.

Our study contains some limitations which should be acknowledged. First, owing to the relatively small sample size, our study may have suffered from limited statistical power. This may have resulted in an inability to identify the interconnections between the categorical transition variables as well as to detect subtle links between latent classes and concurrent wellbeing correlates. Second, although latent class analysis provides a tool for exploring the interconnections among a set of categorical variables, one should be cautious about attaching too much meaning to a latent class or to a label assigned to it (Sandefur, Eggerling-Boeck and Park 2005). Third, the patterns of adult role combinations were identified at age 27 , and thereby, they represent only a snapshot in time. Therefore, our patterns do not capture the dynamic nature of the transition process. For instance, it is possible that individuals in the Workorientation pattern may have established a family later on. Using latent transition analysis, one could study change in class membership (Macmillan and Copher 2005; Oesterle et al 2010). Fourth, psychosocial wellbeing was measured at the same age as the transitional domains used in latent class analysis. Therefore, no conclusions can be drawn regarding the causality between psychosocial wellbeing and adult role combinations. Considering the limitations, studies with larger samples are needed in the future to confirm our results regarding patterns of adult role combinations, their antecedents in childhood and psychosocial wellbeing implications in adulthood. Furthermore, the examination of how role transitions regarding housing, education, work, partnership, and parenthood intersect and are linked across time, would be worth a separate study in the future.

Our study contributed to the existing research regarding transition to adulthood, first by considering the occurrence of five key adult transitions (i.e. moving from parental home into independent living, completion of full-time education, starting a full-time job, establishment of an intimate relationship, and becoming a parent (Furstenberg, Rumbaut and Settersten 2005; Shanahan 2000) simultaneously, rather than as isolated life events. The importance of taking the inter-relation of the adult transitions into account has been highlighted by Furstenberg and his colleagues (2005). Second, our analyses were based on a representative sample of Finns born in 1959. Third, we used a longitudinal approach, which enabled us to investigate contextual and individual childhood antecedents of the patterns of adult role combinations, as well as concurrent psychosocial wellbeing correlates of the patterns within the same individuals, adjusting for the childhood antecedents. 


\section{Acknowledgements}

The preparation of this article was funded by the Academy of Finland through grants (118316 and 135347) awarded to Katja Kokko and the grant (127125) awarded to Lea Pulkkinen. This material was also based upon work supported by the U.S. National Science Foundation under Grant No. 0818478. Any opinions, findings, and conclusions or recommendations expressed in this material are those of the authors and do not necessarily reflect the views of the National Science Foundation. We also acknowledge Arthur $\mathrm{H}$ Sakamoto for his mathematical assistance with relative risks and their standard deviations.

\section{References}

Amato PR, Landale NS, Havasevich-Brooks TC, Booth A, Eggebeen DJ, Schoen R and McHale SM. (2008) Precursors of young women's family formation pathways. Journal of Marriage and Family, 70, 1271-1286.

Arnett JJ. (2000) Emerging adulthood: A theory of development from the late teens through the twenties. American Psychologist, 55, 469-480.

Caspi A, Moffitt TE, Thornton A, Freedman D, Amell JA, Harrington H, Smeijers J and Silva PA. (1996) The life history calendar: A research and clinical assessment method for collecting retrospective event-history data. International Journal of Methods in Psychiatric Research, 6, 101-114.

Celeux G and Soromenho G. (1996) An entropy criterion for assessing the number of clusters in a mixture model. Journal of Classification, 13, 195-212.

Cohen P, Kasen S, Chen H, Hartmark C and Gordon K. (2003) Variations in patterns of developmental transmissions in the emerging adulthood period. Developmental Psychology, 39, 657-669.

Daukantaite D and Zukauskiene R. (2006) Swedish and Lithuanian employed women's subjective well-being. International Journal of Social Welfare, 15 (Suppl 1), S23-S30.

Elder GH. (1998) The life course and human development. In W Damon and RM Lerner. eds. Handbook of child psychology, Volume 1, Theoretical models of human development (5th ed.). Pp 939-991. Hoboken, NJ.

Elder GH, Kirkpatrick Johnson M and Crosnoe R. (2003) The emergence and development of life course theory. In JT Mortimer and MJ Shanahan. eds. Handbook of the Life Course. Pp. 3-18, Springer, New York.

Feldt T, Mäkikangas A and Aunola K. (2006) Sense of coherence and optimism: A more positive approach to health. In L Pulkkinen, J Kaprio and RJ Rose. eds. Socioemotional development and health from adolescence to adulthood. Pp. 286-305, Cambridge University Press, New York.

Furstenberg FF, Rumbaut RG and Settersten RA. (2005), On the Frontier of Adulthood: Emerging Themes and New Directions. In RA Settersten, FF Furstenberg and RG Rumbaut. eds. On the frontier of adulthood: Theory, research, and public policy. Pp. 3-25. University of Chicago Press, Chicago and London.

Fussell E and Furstenberg FF. (2005) The Transition to Adulthood during the Twentieth Century: Race, Nativity, and Gender. In RA Settersten, FF Furstenberg and RG Rumbaut. eds. On the frontier of adulthood: Theory, research, and public policy. eds. Pp 29-75. University of Chicago Press, Chicago and London.

Kokko K, Pulkkinen L and Mesiäinen P. (2009) Timing of parenthood in relation to other life transitions and adult social functioning. International Journal of Behavioral Development, 33, 356-365.

Kokko K, Pulkkinen L, Mesiäinen P and Lyyra A-L. (2008) Trajectories based on postcomprehensive and higher education: Their correlates and antecedents. Journal of Social Issues, 64, 59-76.

Lazarsfeld PF and Henry NW. (1968) Latent structure analysis. Houghton Mifflin, Boston.

Lee $\mathrm{C}$ and Gramotnev H. (2007) Life transitions and mental health in a national cohort of young Australian women. Developmental psychology, 43, 877-888.

Lehto A and Sutela H. (2008) Työolojen kolme vuosikymmentä-Työolotutkimusten tuloksia 1977-2008. Tilastokeskus, Helsinki.

Macmillan R and Copher R. (2005) Families in the life course: Interdependency of roles, role configurations, and pathways., Journal of Marriage and Family, 67, 858-879.

Muthen B and Muthen LK. (2000) Integrating person-centered and variable-centered analyses: Growth mixture modeling with latent trajectory classes., Alcoholism: Clinical and Experimental Research, 24, 882-891.

Múthen L and Múthen B. (1998-2010) Mplus User's Guide. Múthen \& Múthen, Los Angeles, CA.

Nikander T. (1998) Fertility and family surveys in countries of the ECE region.Standard country report: Finland. United Nations, New York - Geneva.

Nylund KL, Asparouhov T and Muthen BO. (2007) Deciding on the number of classes in latent class analysis and growth mixture modeling: A Monte Carlo simulation study. Structural Equation Modeling, 14, 535-569.

Oesterle S, Hawkins JD, Hill KG and Bailey JA. (2010) Men's and women's pathways to adulthood and their adolescent precursors. Journal of Marriage and Family, 72, 1436-1453. 
Osgood DW, Ruth G, Eccles JS, Jacobs JE and Barber BL. (2005) Six Paths to Adulthood: Fast Starters, Parents without Careers, Educated Partners, Educated Singles, Working Singles, and Slow Starters. In RA Settersten, FF Furstenberg and RG Rumbaut. eds. On the frontier of adulthood: Theory, research, and public policy. Pp. 320355. University of Chicago Press, Chicago and London.

Pitkänen T, Kokko K, Lyyra A-L and Pulkkinen L. (2008) A developmental approach to alcohol drinking behaviour in adulthood: A follow-up study from age 8 to age 42. Addiction, 103, Suppl 1, 48-68.

Pitkänen T, Lyyra A-L and Pulkkinen L. (2005) Age of onset of drinking and the use of alcohol in adulthood: A follow-up study from age 8-42 for females and males. Addiction, 100, 652-661.

Pulkkinen L. (2006), The Jyväskylä Longitudinal Study of Personality and Social Development. In L Pulkkinen, J Kaprio and RJ Rose. eds. Socioemotional development and health from adolescence to adulthood. Pp 29-55. Cambridge University Press, New York.

Pulkkinen L and Kokko K. (2010) Keski-ikä elämänvaiheena [Middle-age as a stage of life], Jyväskylän yliopisto, Jyväskylä.

Pulkkinen L, Lyyra A-L and Kokko K. (2009) Life success of males on nonoffender, adolescence-limited, persistent, and adult-onset antisocial pathways: Follow-up from age 8 to 42. Aggressive Behavior, 35, 117-135.

Pulkkinen L and Rönkä A. (1994) Personal control over development, identity formation, and future orientation as components of life orientation: A developmental approach. Developmental Psychology, 30, 260-271.

Räikkönen E, Kokko K and Rantanen J. (2011) Timing of adult transitions: Antecedents and implications for psychological functioning. European Psychologist, 16, 314-323.

Raivola R, Zechner M and Vehviläinen J. (2000), Opintotuki-Opiskelijapalkka vai koulutusinvestointi [Study grants-A salary for students or investment in education]. Ministry of Education and Culture Publications, 14, 2000.

Reitzle M and Vondracek FW. (2000) Methodological avenues for the study of career pathways. Journal of vocational behavior, 57, 445-467.

Rönkä A, Kinnunen U and Pulkkinen L. (2000) The accumulation of problems of social functioning as a long-term process: Women and men compared. International Journal of Behavioral Development, 24, 442-450.

Ross A, Schoon I, Martin P and Sacker A. (2009) Family and nonfamily role configurations in two British cohorts. Journal of Marriage and Family, 71, 1-14.

Saarikallio M and Ylöstalo P. (2007) Lapsiperheet jäivät vähemmistöksi asumistuen saajissa. Sosiaalivakuutus, 45, 40-42.

Sahlberg P. (2011) Finnish lessons: What can we learn from educational change in Finland? Teachers College Press, New York, USA.

Salmela-Aro K, Ek E, Taanila A and Chen M. (2012) Role status configurations of young adulthood, antecedents, and later wellbeing among Finns born in 1966. Longitudinal and Life Course Studies, 3, 228-242.

Sandefur GD, Eggerling-Boeck J and Park H. (2005) Off to a Good Start? Postsecondary Education and Early Adult Life. In RA Settersten, FF Furstenberg and RG Rumbaut. eds. On the frontier of adulthood: Theory, research, and public policy. Pp. 292-319. The University of Chicago Press, Chicago and London.

Schoon I, Martin P and Ross A. (2007) Career transitions in times of social change. His and her story. Journal of vocational behavior, 70, 78-96.

Schoon I and Silbereisen RK. (2009) Conceptualising school-to-work transitions in context. In I Schoon and RK Silbereisen. eds. Transitions from school to work: Globalization, individualization, and patterns of diversity. $\mathrm{Pp}$ 3-29. Cambridge University Press, New York.

Schulenberg JE, Bryant AL and O'Malley PM. (2004) Taking hold of some kind of life: How developmental tasks relate to trajectories of well-being during the transition to adulthood. Development and psychopathology, 16, 11191140.

Schulenberg J, O'Malley PM, Bachman JG and Johnston LD. (2005) Early adult transitions and their relation to wellbeing and substance use. In RA Settersten Jr, FF Furstenberg and RC Rumbaut. eds. On the frontier of adulthood: Theory, research, and public policy. Pp. 417-453. University of Chicago Press, Chicago.

Schwartz G. (1978) Estimating the dimension of a model. The Annals of Statisics, 6, 461-464.

Sclove L. (1987) Application of model-selection criteria to some problems in multivariate analysis. Psychometrika, 52, 333-343.

Shanahan MJ. (2000) Pathways to adulthood in changing societies: Variability and mechanisms in life course perspective. Annual Review of Sociology, 26, 667-692.

Staff J, Schulenberg JE, Maslowsky J, Bachman JG, O'Malley PM, Maggs JL and Johnston LD. (2010) Substance use changes and social role transitions: Proximal developmental effects on ongoing trajectories from late adolescence through early adulthood. Development and Psychopathology, 22, 917-932.

Statistics Finland. (1994) Suomalainen lapsiperhe [The Finnish family with children], Hakapaino Oy, Helsinki, Finland.

Statistics Finland. (2003) Statistical yearbook of Finland 2003, Karisto Oy, Hämeenlinna, Finland.

Vondracek FW, Lerner RM and Schulenberg JE. (1986) Career development : a life-span developmental approach. Erlbaum, Hillsdale NJ. 